\title{
A FUNÇÃO SOCIAL DA PROPRIEDADE E O IPTU PROGRESSIVO: ANÁLISE DOS MUNICÍPIOS GAÚCHOS COM MAIS DE 50.000 HABITANTES
}

\author{
THE SOCIAL FUNCTION OF PROPERTY AND PROGRESSIVE IPTU: \\ ANALYSIS OF THE MUNICIPALITIES IN THE STATE OF RIO GRANDE DO SUL WITH MORE THAN \\ 50.000 INHABITANTS
}

\author{
Giovani da Silva Corralo \\ Doutor em Direito pela UFPR \\ Universidade de Passo Fundo \\ Passo Fundo/RS. Brasil \\ gcorralo@upf.br \\ (iD) Diego Mattjie \\ Graduado em Ciências Jurídicas e Sociais \\ Universidade de Passo Fundo \\ Passo Fundo/RS. Brasil \\ 141279@upf.br
}

Resumo: A presente pesquisa analisa a função social da propriedade urbana, especialmente através da incidência do IPTU progressivo, nos municípios gaúchos com mais de 50.000 habitantes. Utiliza-se o método hipotético-dedutivo para perscrutar a hipótese da ineficácia jurídica do IPTU progressivo nesses municípios gaúchos. O trabalho está divido em dois capítulos, o primeiro a refletir sobre a função social da propriedade no ordenamento jurídico brasileiro, mais especificamente a propriedade urbana; o segundo capítulo a analisar os planos diretores e a legislação municipal para identificar a existência dos requisitos legais para a eficácia jurídica do parcelamento, edificação e utilização compulsórios e do IPTU progressivo. Conclui-se pela baixíssima eficácia jurídica do IPTU progressivo, uma vez que apenas 13,3\% dos municípios estudados atendem aos requisitos legais para a sua eficácia.

Palavras-chave: Estatuto da Cidade. IPTU progressivo. Municípios gaúchos.

\begin{abstract}
This research analyzes the social function of urban property, especially through the incidence of progressive IPTU, in the municipalities of Rio Grande do Sul with more than 50.000 inhabitants. The hypothetical-deductive method is used to examine the hypothesis of the legal ineffectiveness of progressive IPTU in these municipalities of the state. The work is divided into two chapters, the first to reflect on the social function of property in the Brazilian legal system, more specifically urban property; the second chapter to analyze the master plans and the municipal legislation to identify the existence of the legal requirements for the legal effectiveness of the compulsory subdivision, building and use of the urban properties and the progressive IPTU. We conclude that the progressive IPTU has a very low legal effectiveness, since only $13,3 \%$ of the studied municipalities have the legal requirements for its effectiveness.
\end{abstract}

Keywords: City Statute. Progressive IPTU. Gaucho municipalities.

Para citar este artigo (ABNT NBR 6023:2018)

CORRALO, Giovani da Silva; MATTJIE, Diego. A função social da propriedade e o IPTU progressivo: análise dos municípios gaúchos com mais de 50.000 habitantes. Revista Thesis Juris - RTJ, São Paulo, v. 9 , n. 2, p. 301-322, jul./dez. 2020. http://doi.org/10.5585/rtj.v9i2.17634. 


\section{Introdução}

A presente pesquisa tem por foco o estudo da função social da propriedade urbana, especialmente através da incidência do Imposto Predial e Territorial Urbano (IPTU) progressivo, nos municípios gaúchos com mais de 50.000 habitantes.

A Constituição de 1988 salientou, no diapasão do regramento constitucional anterior, a função social da propriedade. Para a propriedade urbana o artigo (art.) 182 resguardou o protagonismo dos municípios, nos termos das diretrizes gerais, fixadas pelo Estatuto da Cidade - Lei $n^{\circ} 10.257 / 2001$. Nessas diretrizes gerais são apontados os instrumentos da política urbana, dos quais se sobressaem o parcelamento, edificação e utilização compulsórios e o IPTU progressivo, que se encontram diretamente imbricados. Para que tais instrumentos tenham efetividade é preciso a sua eficácia jurídica, o que somente ocorre quando devidamente absorvidos na legislação local, cuja centralidade para a política urbana é o Plano Diretor.

Para que o IPTU progressivo possa ser implementado é preciso: a) legislação municipal que discipline a matéria, a observar os limites do Estatuto da Cidade; b) que o Plano Diretor preveja as áreas de incidência, que podem ocorrer em todo o espaço urbano; c) que o Plano Diretor ou legislação correlata defina os critérios de subutilização, não parcelamento e não edificação; e d) lei específica para a área ou áreas incluídas no Plano Diretor que determine o parcelamento, a edificação ou a utilização compulsórios, com condições, prazos de implementação e alíquotas do IPTU progressivo.

Em razão de se utilizar o método hipotético-dedutivo, perscruta-se a hipótese da ineficácia jurídica do IPTU progressivo nos municípios gaúchos com mais de 50.000 habitantes, desdobrados em dois grupos: de 50.000 habitantes a 100.000 habitantes e mais de 100.001 habitantes. Para essa aferição foram analisados os planos diretores dos 45 municípios gaúchos com mais de 50.000 habitantes, como também eventuais legislações correlatas e específicas sobre a matéria, utilizando-se dos sistemas de buscas nos sites oficiais das municipalidades em comento.

Por conseguinte, o trabalho está dividido em dois capítulos. O primeiro reflete sobre a função social da propriedade no ordenamento jurídico brasileiro, mais especificamente a propriedade urbana, com base na Constituição Federal e no Estatuto da Cidade. Também analisa as diferenças entre posturas mais liberais e mais intervencionistas. O segundo capítulo, a pressupor a autonomia local para a definição dos instrumentos previstos no Estatuto da Cidade, analisa os planos diretores e respectivas leis para identificar: planos diretores que contemplem o IPTU progressivo; planos diretores que delimitem as áreas de aplicação do parcelamento, 
edificação ou utilização compulsórios; existência de critérios para imóvel subutilizado, não utilizado e não parcelado; e a existência de alíquotas do IPTU progressivo.

O Estatuto da Cidade, no alto dos seus 19 anos de existência, já ultrapassou a maioridade. Para uma melhor análise da eficácia jurídica dos seus institutos, no caso concreto do parcelamento, edificação e utilização compulsórios do IPTU progressivo, é preciso examinar a legislação municipal, com ênfase aos planos diretores. É o que se busca.

\section{A função social da propriedade urbana e o Estatuto da Cidade}

O direito de propriedade, assim como a religião doméstica e a família, acha-se alicerçado e fundado firmemente desde as mais antigas sociedades itálica e grega, sendo um dos caracteres recorrentes em todo o desenvolvimento da história do Ocidente (COULANGES, 1998). De fato, nas referidas sociedades, a propriedade se relacionava intimamente com a noção de família, encontrando-se sob a guarda do deus doméstico (COMPARATO, 1997). Não é de se admirar, portanto, que aquele direito tenha sido objeto das mais variadas avaliações e ponderações.

A propriedade, segundo Rousseau (1999), apresenta-se, ao mesmo tempo, como razão de ser da sociedade e como desencadeadora dos males e desigualdades sociais. Referido autor, inclusive , relaciona o fundamento da sociedade civil com a afirmação do direito de propriedade, asseverando que o direito de propriedade, por ser uma criação humana, deriva do acordo mútuo e geral estabelecido pelos indivíduos que compõem a sociedade.

Locke (1994), por seu turno, entrelaça os conceitos de propriedade e de liberdade, no sentido que aquele é decorrente deste último, ou seja, da própria liberdade humana. Além disso, a propriedade, na sua visão, deve possuir vínculo estreito com a produtividade, pois ao proprietário que tornar os bens que possui produtivos deve ser reconhecido o direito de propriedade. Assim, pode-se vislumbrar, de certa forma, pressupostos para que se considere que alguém seja proprietário de alguma coisa, quais sejam: a apropriação dos bens deve se dar em razão do trabalho e com o intuito de aumentar a produção daquilo que se apropriou.

É nesse contexto que a propriedade é encarada como um direito sagrado, nos moldes segundo os quais a própria Declaração dos Direitos do Homem e do Cidadão de 1789 dispôs em seu texto (FERREIRA FILHO, 1982).

A propriedade e, em especial, a propriedade urbana, se relaciona diretamente com a força produtiva existente em um específico local físico e político, bem como com o modelo de Estado encarregado de promover o arranjo dos rumos de cada sociedade (LEAL, 1998). Com 
efeito, as normas jurídicas, de uma maneira geral, bem como as disposições constitucionais, em particular, relacionam-se com algum fator real de poder, isso porque asseguram, por meio de garantias e obrigações, o atendimento de certos e determinados interesses (MORAES, 1999).

Nesse ínterim, a concepção liberal encarava o direito à propriedade como um direito absoluto, na medida em que o mesmo era concebido como um direito natural e inviolável. A propriedade era considerada, em suma, como o direito primordial que possibilitaria aos indivíduos desenvolverem-se na sociedade. É sob essa perspectiva que se sustenta a legitimação da propriedade durante o liberalismo econômico (FROSI, 1998). A visão adotada relacionava intimamente as concepções de liberdade e de propriedade, já que a condição de ser proprietário expressava o caráter de ser livre (OLIVEIRA; LACERDA, 2011). É dessa forma que, segundo o ideário burguês que surgia na época, a propriedade consubstanciava, efetivamente, a pura acepção de utilidade econômica (COMPARATO, 1997).

Dentro dessa perspectiva, o constitucionalismo consagrado a partir do século XVIII visava limitar os poderes estatais e estabelecer sua organização. A ideia que imperava era a de que o Estado deveria estar alheio às relações estabelecidas entre os particulares. Isso porque, desta maneira, estariam garantidos os direitos individuais e o desenvolvimento dos indivíduos em sociedade estaria resguardado diante da limitação estatal. Essa noção de igualdade, em seu aspecto eminentemente formal, amoldou-se perfeitamente aos ideais liberais nascentes (MORAES, 1999).

Enquanto o Estado liberal assenta seus pressupostos em alicerces individualistas, tendo moldado a construção da ideia moderna de liberdade, conquanto inegável a sua contribuição para os arranjos de limitação do Estado e separação de poderes, sua insuficiência teórica e prática deu azo a novas perspectivas que surgiram e culminaram na reinterpretação do modelo formal de liberdade, o que acarretou a sua superação em favor do Estado social, de índole essencialmente marcada pela intervenção estatal (BONAVIDES, 1996).

Nesse contexto, após a bem-sucedida revolução burguesa, o ideário da propriedade liberal se deparou com questões que não era capaz de encarar e responder satisfatoriamente, diante da constatação de que várias das conquistas alcançadas durante a Revolução Francesa haviam sido apenas atendidas parcialmente (FROSI, 1998). A emergência do Estado social, ulteriormente ao Estado liberal, se deu em razão de uma necessidade da modernidade (BONAVIDES, 1996), atenta às demandas sociais, mas, antes de tudo, preocupada em manter e perpetuar o modelo de dominação econômico-social já existente.

A autonomia individual, entendida no constitucionalismo clássico e no sistema liberal, era um preceito que deveria ser garantido a qualquer preço, mesmo que em detrimento das 
massas trabalhadoras que compunham a maior parte da população (MORAES, 1999). Só que a ausência quase que completa de interferência estatal em assuntos relacionados à economia e, em especial, ao direito de propriedade, acabou por acentuar distorções sociais, com a concentração dos meios de produção e de riqueza dispostos em favor da busca de um sobredito desenvolvimento que, na realidade, não atendia a todos da mesma maneira. Assim, o desgaste da concepção clássica do direito de propriedade privada foi se perpetuando no tempo, ora de maneiras mais acentuadas, ora de maneiras mais sutis, mas nunca se deixando apagar (FROSI, 1998).

Importante contribuição para essa mudança paulatina de posicionamento do Estado em relação a sua interferência no campo econômico se deu com a doutrina positivista de Auguste Comte, em meados do século XIX (FROSI, 1998). Comte (1978) aduzia que parte das desordens sociais existentes à época derivava do interesse desmedido da pequena burguesia em detrimento das necessidades das massas populares, avaliando que a concentração de bens e riquezas na mão de uma minoria deveria ser exercida de maneira responsável, para também satisfazer os interesses da maioria proletária. Tem-se uma nítida ideia de que os cidadãos são, sob esse prisma, considerados como funcionários sociais, onde " $\mathrm{O}$ positivismo não admite nunca senão deveres de todos para com todos [...]" (COMTE, 1978, p. 278).

Em sua lição já clássica, Duguit (1987) supera a visão objetiva do direito de propriedade e vai além, ao relacionar os conceitos de liberdade e de função social. A propriedade não é tomada como pura e simplesmente um direito, mas, em âmbito diametralmente oposto, como uma função social, onde o possuidor, desde que atenda a esta última, está assegurado em seu direito, ao passo em que se vier a não a cumprir restará desprotegido. É por isso que a interferência governamental na propriedade que não se conformar aos ditames sociais é legítima, segundo o autor referenciado.

A propriedade passa a ser encarada sob um viés social, deixando de lado o ideário de simples direito individual e absoluto. É o momento em que a propriedade liberal ganha temperamentos, os quais tem por finalidade a salvaguarda e a realização da justiça social, através da utilidade coletiva, embora seja oportuno se destacar que as legislações da época vacilavam em garantir tais ideais ora de forma explícita ora de maneira implícita (OLIVEIRA; LACERDA, 2011).

Contudo, o advento da Primeira e, especialmente, da Segunda Guerra Mundial, aliado à variada e multifacetária composição ideológica existente, assentou, de forma mais contundente, a ideia de que o Estado, que se manifestava preponderantemente por meio de prestações negativas e assecuratórias de direitos individuais não tinha o poder, mas o dever de proporcionar 
melhores condições de vida para os seus cidadãos. E uma das formas para o fazer era intervindo na propriedade privada, normatizando o seu exercício e impondo limitações ao seu desempenho (FROSI, 1998).

São estes momentos disruptivos que provocam profundas transformações nas relações estabelecidas entre o Estado e os particulares. Rompe-se, assim, com o paradigma do "[...] constitucionalismo clássico do século XVIII, dando vezo ao surgimento de um constitucionalismo mais social [...]” (LEAL, 1998, p. 103). Consequentemente, passa-se a encarar o direito de propriedade além do seu aspecto jurídico, para englobar, também, questionamentos de ordem política e social (LEAL, 1998).

O desenvolvimento do direito de propriedade, especialmente urbana, passa a se dar em sentido diametralmente oposto às suas concepções originais, de cunho individual, para se preocupar com questões de caráter social. A ordem jurídica não se dispõe a proteger apenas o direto subjetivo de uso e fruição do proprietário, mas tutela e regula a liberdade do proprietário em atender a função social que lhe cabe, justamente porque é ele o titular da riqueza (LEAL, 1998).

Comparato (1997) assevera que a propriedade passa a se apresentar como um direitomeio, não um simples direito-fim, já que ela deve ser entendida como um meio de proteção de preceitos fundamentais, não um mero exaurimento em si mesma. No mesmo sentido, Oliveira e Lacerda (2011) vislumbram tal caráter dual da propriedade, na medida em que ela se relaciona a um poder, vinculado ao exercício das faculdades de disposição do proprietário, e a um dever, que possui laços estreitos com a sociedade e o Estado. Assim, com essa nova percepção do direito de propriedade, altera-se a visão consagrada no modelo liberal puro.

Todavia, não se pode perder de vista que a superação do Estado liberal se deu de forma paulatina e de diferentes maneiras, não tendo se operado de maneira linear. Com efeito, a soberania do público sobre o privado surge como resposta ao Estado mínimo consagrado nos moldes liberais, marcando sua derrocada, embora não a sua supressão definitiva (BOBBIO, 2005).

É necessário ter em mente que, embora o modelo econômico consagrado pelo liberalismo tenha sido superado, o chamado Estado social não superou ou suprimiu todos os seus caracteres de forma definitiva. Antes, deve-se compreender que houve uma mudança de paradigmas, no sentido de que o dirigismo econômico, até os dias de hoje, tenta se conciliar com o modelo político liberal, mesmo que as suas consequências nem sempre se mostrem as mais justas (LEAL, 1998).

Tanto as constituiçõos de índole liberal quanto os Estados-providência cuidaram de 
regular o direito de propriedade, cada um ao seu modo. Tal não foi diferente no direito brasileiro. Nesse espectro, as duas primeiras constituições nacionais trataram de tal assunto de maneira estreitamente relacionada com o liberalismo econômico. A partir de então, verificouse uma mudança paulatina no sentido de se atribuírem limites à propriedade, até se culminar na menção expressa da função social da propriedade na redação da Constituição de 1967, tendo tal matéria permanecido regulada e desenvolvida até a Constituição vigente (FERREIRA FILHO, 1982).

A ampliação dos direitos fundamentais, especialmente depois das graves consequências dos eventos bárbaros do século passado, abriu maior margem para o questionamento e julgamento do sistema capitalista (LEAL, 1998).

Nessa mudança de perspectivas, as decisões políticas tomadas exigem que seu fundamento seja balizado por parâmetros que não apenas fixem os seus limites, mas que, ainda, sejam o seu próprio fundamento de validade constitucional (CANOTILHO, 1994). É por isso que se pode afirmar que "[...] a constituição programático-dirigente não substitui a política, mas torna-se premissa material da política.” (CANOTILHO, 1994, p. 487). De fato, é a Constituição, dotada de força normativa, que serve como fundamento das demais normas componentes de um sistema jurídico e exprime os valores imperantes em um determinado momento (MORAES, 1999).

Nesse ambiente, a concepção da propriedade agregou uma nova visão e fundamentos, não se apresentando mais no seu sentido clássico absoluto, mas orientada à harmonização do exercício dos interesses individuais com os de índole coletiva, ou seja, sua função social, a qual se encontra presente na maioria das codificações dos países ocidentais (LEAL, 1998).

Embora o intervencionismo na propriedade, mais latente na propriedade urbana, marque uma preocupação de cunho eminentemente social, o direito à propriedade privada é assegurado porquanto é dele que se satisfazem os interesses da própria sociedade em uma economia capitalista. Contudo, esse sistema econômico não se apresenta de forma isolada da realidade social, porquanto sofre temperamentos, especialmente por vieses de caráter marcadamente social, tal como a noção de função social (MORAES, 1999). É nesse contexto que se concebe a limitação do direito de propriedade.

Pode-se dizer, assim, que a função social da propriedade tem caráter assecuratório ambivalente, ao passo em que garante o direito de o proprietário não ser molestado no seu regular exercício e ao possibilitar a intervenção na propriedade que não se conformar com o interesse social correlato a sua existência (MORAES, 1999). A ideia de função social da propriedade se relaciona intimamente com a noção e preservação da propriedade privada, isso 
porque à propriedade só é instituída a ideia de função social justamente por ela possuir a qualidade de ser privada (GRAU, 2007).

De fato, é durante a Segunda República que o Brasil passa a apresentar nova orientação filosófico-jurídico-administrativa, consubstanciada em inovações do que se costuma definir como Estado social (LEAL, 1998). O proprietário, para atender a função social da propriedade, se coloca, por assim dizer, como um procurador da sociedade, já que a administração de seus bens deve atender, simultaneamente, tanto os seus interesses particulares quanto aqueles relacionados às exigências sociais (FERREIRA FILHO, 1982), sem que com isso se supere, de maneira definitiva, o caráter privado da propriedade.

Essa mudança de perspectivas fica clara quando se analisa o tratamento topológico dado pelos textos constitucionais à função social da propriedade: enquanto as constituições passadas apenas referiam a função social da propriedade quando tratavam da ordem econômica, o texto magno atual faz alusão a ela quando trata dos direitos e garantias fundamentais, bem como da ordem econômica, da política urbana e da política agrícola e fundiária. Apenas com a Constituição Federal de 1988 sobredito direito grassou ter a relevância que possui atualmente (DENALDI et al., 2015), momento no qual a função social da propriedade alcança maior importância e abrangência.

A Constituição Federal de 1988, nesse sentido, embora consagre expressamente que a propriedade deve se conformar ao atendimento da sua função social, em seu art. $5^{\circ}$, XXIII, e declare a função social da propriedade como um princípio da ordem econômica nacional, conforme se depreende da análise de seu art. 170, III, igualmente assegura o caráter particular da propriedade, nos próprios artigos $5^{\circ}$, XXII, e 170, II. Ou seja, a ordem constitucional, longe de suprimir o caráter privado da propriedade, cuida de impor limitações ao exercício do direito de propriedade, o qual deve se conformar com valores relacionados com a justiça social, notadamente a própria função social.

Tendo em vista a ordem constitucional estabelecida, é a partir da promulgação da Lei $n^{\text {o }} 10.257 / 2001$, conhecida como Estatuto da Cidade, que a ordenação do planejamento urbano toma novos rumos. Regulamentando os artigos 182 e 183 da Constituição Federal de 1988, que tratam da política urbana, referida Lei tem como escopo "[...] ordenar o pleno desenvolvimento das funções sociais da cidade e garantir o bem-estar de seus habitantes." (MARQUES, 2018, p. 94).

De fato, o Estatuto da Cidade se consubstancia em uma norma de caráter nacional que define um modelo de planejamento urbanístico a ser seguido, elencando entre suas diretrizes princípios de caráter constitucional, tal como o da função social da propriedade, do 
desenvolvimento sustentável e das funções sociais da cidade (MARQUES, 2018), inclusive com a consagração do princípio da dignidade da pessoa humana, vinculando o próprio sistema capitalista (FIORILLO, 2014), que não pode se desenvolver em simples detrimento da realidade jurídica e social. Assim, constata-se que o Estado tem o poder e, inclusive, o dever de trazer diretrizes para a intervenção no domínio econômico, notadamente na propriedade urbana, sem, contudo, levar à supressão do próprio direito à propriedade privada e o seu regular exercício.

Importante ser destacado que o Estatuto da Cidade, embora regulamente os dispositivos constitucionais supramencionados, não exaure a matéria, devendo ser entendido em âmbito diametralmente oposto, na medida em que estatui apenas regras gerais que devem ser observadas pelos planos diretores e demais leis correlatas de cada município (COSTA; SANTORO, 2019), os quais necessitam observar tanto as disposições do Estatuto quanto a normatização geral da ordem constitucional.

Da análise do Estatuto da Cidade, verifica-se que o mesmo dispôs uma série de mecanismos voltados ao atendimento da função social da cidade e da propriedade, tentando fazer frente aos desafios das questões relacionadas à urbanização no país (BRAJATO; DENALDI, 2019), entre os quais podem ser citados, exemplificativamente, o parcelamento, a edificação e a utilização compulsórios, o IPTU progressivo no tempo e o direito de preempção.

De fato, o Estatuto da Cidade se apresentou como uma nova maneira de realizar o planejamento urbano, instituindo o Plano Diretor como o instrumento básico da política de desenvolvimento e expansão urbana (RIBEIRO, 2004), conferindo, por consequência, maior importância a ele.

Ainda assim, a despeito das considerações efetuadas, não se deve perder de vista o histórico patrimonialista sobre o qual foi construída a sociedade brasileira, o que resulta, não raras vezes, na dificuldade de aplicação da legislação, inclusive no que toca à função social da propriedade e aos seus desdobramentos (BRAJATO; DENALDI, 2019).

Inobstante as particularidades fáticas e teóricas acerca da matéria, o Plano Diretor apresenta-se como meio crucial para a ordenação e conformação da ordem territorial. E, para que tal possa ocorrer, necessita lançar mão de instrumentos capazes de, efetivamente, ordenar a cidade. É nesse ínterim que se destaca a possibilidade da instituição do IPTU progressivo no tempo, com vistas a combater o caráter meramente especulativo dos imóveis, o que acaba por concretizar uma das formas de atendimento do princípio da função social da propriedade.

São sob essas perspectivas, onde tentam ser harmonizados os interesses individuais da ordem jurídica capitalista com valores afetos ao bem-estar da coletividade e da função social da propriedade que se desenvolve e deve ser entendido o direito da propriedade urbana 
CORRALO, Giovani da Silva; MATTJIE, Diego. A função social da propriedade e o IPTU progressivo: análise dos municípios gaúchos com mais de $\mathbf{5 0 . 0 0 0}$ habitantes

hodiernamente.

\section{A eficácia jurídica do Imposto Predial e Territorial Urbano progressivo no tempo nos municípios gaúchos com mais de $\mathbf{5 0 . 0 0 0}$ habitantes}

A repartição de competências na Federação brasileira em matéria urbanística remete à União a elaboração de normas gerais e diretrizes para o desenvolvimento urbano, enquanto que Estados, Distrito Federal e Municípios disciplinam localmente essa matéria, a salientar a competência municipal para a execução das políticas de desenvolvimento urbano, que têm nos planos diretores ou legislação urbanística correlata a centralidade normativa ${ }^{1}$.

Vários são os instrumentos da política urbana para concretizar as diretrizes do Estatuto da Cidade, que podem ser sistematizados em quatro campos distintos e complementares: a) função social da propriedade e da cidade; b) cidades sustentáveis; c) planejamento e gestão democrática; e d) direitos fundamentais. O Plano Diretor, obrigatório para os municípios com mais de 20.000 habitantes, deve ser instituído por lei específica, nos termos da Lei Orgânica Municipal, constituindo-se em condição legal e imprescindível para a concretização das diretrizes previstas no Estatuto da Cidade (CORRALO, 2011).

Mais especificamente quanto à função social da propriedade, é o Plano Diretor que deve definir a aplicabilidade dos instrumentos de indução ao desenvolvimento urbano. É o que ocorre com um dos principais instrumentos para tal desiderato: o parcelamento, edificação ou utilização compulsórios - essenciais para a efetividade do IPTU progressivo ${ }^{2}$. Aliás, devem os municípios delimitar as áreas urbanas sobre as quais o parcelamento, edificação ou utilização compulsórios poderão incidir, uma vez que se trata de disposição normativa obrigatória do Plano Diretor ${ }^{3}$. Pode, naturalmente, ocorrer a incidência desses instrumentos em todo o espaço urbano, desde que não haja previsão de área específica e se tenha critérios objetivos para a sua aplicação.

Assim, para a eficácia jurídica do parcelamento, edificação e utilização compulsórios é preciso, cumulativamente: a) legislação municipal que discipline a matéria, a observar os limites do Estatuto da $\mathrm{Cidade}^{4}$; b) que o Plano Diretor preveja as áreas de incidência, que podem

\footnotetext{
${ }^{1}$ Constituição Federal, art. 21, XX; art. 24, I; art. 182; e art. 30, VIII.

${ }^{2}$ Artigos $5^{\circ}$ a $7^{\circ}$ do Estatuto da Cidade.

${ }^{3}$ Estatuto da Cidade: “Art. 42. O plano diretor deverá conter no mínimo: I - a delimitação das áreas urbanas onde poderá ser aplicado o parcelamento, edificação ou utilização compulsórios, considerando a existência de infra-estrutura e de demanda para utilização, na forma do art. $5^{\circ}$ desta Lei; [...]”.

${ }^{4}$ Estatuto da Cidade: "Art. $4^{\mathrm{o}}[\ldots] \S 1^{\circ}$ Os instrumentos mencionados neste artigo regem-se pela legislação que lhes é própria, observado o disposto nesta Lei. [...]”; "Art. $5^{\circ}$ Lei municipal específica para área incluída no plano diretor poderá determinar o parcelamento, a edificação ou a utilização compulsórios do solo urbano não edificado, subutilizado ou não utilizado, devendo fixar as condições e os prazos para implementação da referida obrigação.".
} 
ocorrer em todo o espaço urbano ${ }^{5}$; c) que o Plano Diretor ou legislação correlata defina os critérios de subutilização, não parcelamento e não edificação ${ }^{6}$; e d) lei específica para a área ou áreas incluídas no Plano Diretor que determine o parcelamento, a edificação ou a utilização compulsórios, com condições, prazos de implementação e alíquotas do IPTU progressivo ${ }^{7}$. Tudo em sintonia com o $\S 4^{\circ}$ do art. 182 da Constituição Federal, que ressalva ser uma faculdade do poder municipal ${ }^{8}$.

Em outras palavras, a função social da propriedade urbana está diretamente associada à disciplina normativa municipal, a se sobressair o parcelamento, edificação e utilização compulsórios e o IPTU progressivo. Há o dever de os municípios definirem as áreas da sua incidência, mas não há a previsão de um mínimo territorial. Além disso, os critérios de subutilização podem ser amplamente disciplinados, seja de forma mais restritiva à propriedade, seja com menos restrições. A autonomia municipal, especialmente na perspectiva legislativa, se impõe (CORRALO, 2014).

São os interesses locais, forjados na convergência dos atores políticos locais, juntamente com os instrumentos de participação e controle sociais - gestão democrática da cidade -, que vão definir uma disciplina normativa mais liberal ou mais restritiva do direito fundamental de propriedade, a lembrar a necessidade de tais limitações observarem os princípios informadores do regime jurídico de direito público, mais especificamente a proporcionalidade, em todas as suas dimensões: adequação, necessidade e sentido estrito ${ }^{9}$. Nesse diapasão se sobressai o princípio da vedação de confisco, que nada mais é do que proibição de desnaturamento do direito de propriedade em razão do tributo progressivo (PONTES, 2017).

O escopo da presente pesquisa não é analisar o mérito das legislações locais sobre o parcelamento, edificação e utilização compulsórios e o IPTU progressivo, até porque tal análise requereria uma crítica teórico-ideológica, influenciada pelos próprios pressupostos de quem analisa. Não é este o foco, até porque se trata de uma pesquisa jurídica. Passados 19 anos do

\footnotetext{
${ }^{5}$ Art. 42 do Estatuto da Cidade, já citado.

${ }^{6}$ Estatuto da Cidade: “Art. $5^{\circ}[\ldots] \S 1^{\circ}$ Considera-se subutilizado o imóvel: I - cujo aproveitamento seja inferior ao mínimo definido no plano diretor ou em legislação dele decorrente; [...]”.

${ }^{7}$ Estatuto da Cidade: "Art. $7^{\circ}$ Em caso de descumprimento das condições e dos prazos previstos na forma do caput do art. $5^{\circ}$ desta Lei, ou não sendo cumpridas as etapas previstas no $\S 5^{\circ}$ do art. $5^{\circ}$ desta Lei, o Município procederá à aplicação do imposto sobre a propriedade predial e territorial urbana (IPTU) progressivo no tempo, mediante a majoração da alíquota pelo prazo de cinco anos consecutivos. $\S 1^{\circ} \mathrm{O}$ valor da alíquota a ser aplicado a cada ano será fixado na lei específica a que se refere o caput do art. $5^{\circ}$ desta Lei e não excederá a duas vezes o valor referente ao ano anterior, respeitada a alíquota máxima de quinze por cento. [...]".

${ }^{8}$ Constituição Federal: “Art. 182. [...] § $4^{\circ}$ É facultado ao Poder Público municipal, mediante lei específica para área incluída no plano diretor, exigir, nos termos da lei federal, do proprietário do solo urbano não edificado, subutilizado ou não utilizado, que promova seu adequado aproveitamento, sob pena, sucessivamente, de: I - parcelamento ou edificação compulsórios; II - imposto sobre a propriedade predial e territorial urbana progressivo no tempo; III - desapropriação com pagamento mediante títulos da dívida pública de emissão previamente aprovada pelo Senado Federal, com prazo de resgate de até dez anos, em parcelas anuais, iguais e sucessivas, assegurados o valor real da indenização e os juros legais."

${ }^{9}$ Segunda Humberto Ávila, a análise da proporcionalidade enquanto adequação pode ser resolvida com a resposta ao seguinte questionamento: o meio é adequado para a concretização dos fins? Quanto à necessidade: trata-se do meio menos restritivo de direitos? Em sentido estrito: o grau de importância do fim justifica o grau de restrição? (ÁVILA, 2004).
} 
Estatuto da Cidade, busca-se analisar, objetivamente, os municípios gaúchos com mais de 50.000 habitantes, conforme estimativa do IBGE de 2019 - num total de 45 -, nos quais estes institutos tenham eficácia jurídica, ou seja, condições de produzir efeitos jurídicos. Também não se analisará a eficácia social ou efetividade dessas normas, em outras palavras, não é alvo desta pesquisa a real aplicação desses institutos e os seus efeitos. É importante lembrar que sem eficácia jurídica não se pode falar em eficácia social ou efetividade (BARROSO, 1993; SARLET, 2006; SILVA, 1964).

Também é importante compreender a dinâmica do parcelamento, edificação e utilização compulsórios e IPTU progressivo. Mesmo que um determinado município disponha, normativamente, de todos esses elementos de forma que possuam eficácia jurídica, é preciso a atuação administrativa para notificar o proprietário acerca da obrigação, o que deve ser averbado no cartório de registro de imóveis. Após a notificação, o proprietário tem o prazo mínimo de um ano - prazo que deve ser definido na legislação local - para protocolar o projeto no órgão competente da municipalidade. Se assim não proceder pode incidir o IPTU progressivo. Se o projeto for protocolado terá o prazo mínimo de dois anos - este prazo também deve estar previsto em lei e estar claramente refletido na notificação -, após a aprovação do projeto, para o seu início, que, se não ocorrer no prazo avençado, possibilita a incidência do IPTU progressivo, nas alíquotas previstas em lei. Nota-se que é plenamente viável que, após notificação, o proprietário consiga protelar por, no mínimo, mais de três anos a incidência do IPTU progressivo. Aos dados dos municípios gaúchos, pois.

A pesquisa de campo teve por foco a análise do IPTU progressivo nos municípios com mais de 50.000 habitantes do Estado do Rio Grande do Sul, num total de 45 municípios, divididos em dois grupos: a) Grupo A: municípios com 50.000 a 100.000 habitantes, num total de 26 municipalidades ${ }^{10}$; e b) Grupo B: municípios com mais de 100.000 habitantes, a totalizar 19 entes locais ${ }^{11}$.

A análise perquiriu quatro objetos: 1 - os planos diretores que dispõem minimamente sobre o parcelamento, edificação e utilização compulsórios e o IPTU progressivo, nos termos do art. $4^{\circ}, \S 1^{\circ}$, do Estatuto da Cidade; 2 - os planos diretores que delimitam as áreas urbanas de aplicação do parcelamento, edificação e utilização compulsórios, nos termos do art. 42, I, do Estatuto da Cidade; 3 - os planos diretores ou legislação correlata que apresentam critérios

\footnotetext{
10 Alegrete, Cachoeira do Sul, Campo Bom, Camaquã, Canguçu, Capão da Canoa, Carazinho, Cruz Alta, Estância Velha, Esteio, Farroupilha, Guaíba, Ijuí, Lajeado, Montenegro, Parobé, Taquara, Tramandaí, São Borja, São Gabriel, Sapiranga, Santa Rosa, Sant'Ana do Livramento, Santo Ângelo, Vacaria e Venâncio Aires.

11 Alvorada, Bagé, Bento Gonçalves, Cachoeirinha, Canoas, Caxias do Sul, Erechim, Gravataí, Novo Hamburgo, Passo Fundo, Pelotas, Porto Alegre, Rio Grande, Santa Cruz do Sul, Santa Maria, São Leopoldo, Sapucaia do Sul, Uruguaiana e Viamão.
} 
minimamente capazes de definir o que seja imóvel subutilizado, não edificado e não parcelado, nos termos do $\S 1^{\circ}$ do art. $5^{\circ}$ do Estatuto da Cidade; 4 - a existência de lei municipal específica a disciplinar as alíquotas progressivas do IPTU em imóveis não utilizados, subutilizados e não parcelados, nos termos do Estatuto da Cidade - art. $7^{\circ}, \S 1^{\circ}$, e art. $5^{\circ}$. O procedimento de pesquisa para concretizar as análises referidas teve por base a busca da legislação nos sites oficiais dos municípios elencados e, não obstante diversas particularidades ${ }^{12}$, foi possível fazer importantes análises conclusivas.

\subsection{Planos Diretores que contemplam o IPTU progressivo}

A totalização mostra que 92,3\% dos municípios do Grupo A dispõem sobre o IPTU progressivo nos seus planos diretores, o que não ocorre com 7,7\% do total. No grupo de maior população, Grupo B, o percentual diminui para $89,5 \%$ de cumprimento, enquanto $10,5 \%$ dos municípios não apresentam essa disciplina normativa, conforme os dados apresentados abaixo.

Tabela 1 - Número de municípios gaúchos com mais de 50.000 habitantes que preveem o IPTU progressivo nos seus planos diretores

\begin{tabular}{c|c|c}
\hline $\begin{array}{c}\text { Municípios } \\
\text { gaúchos }\end{array}$ & $\begin{array}{c}\text { Plano Diretor contempla o IPTU } \\
\text { progressivo }\end{array}$ & $\begin{array}{c}\text { Plano Diretor não contempla o IPTU } \\
\text { progressivo }\end{array}$ \\
\hline Grupo A (1) & $24^{13}$ & 02 \\
Grupo B (2) & $17^{14}$ & 02 \\
TOTAL & 41 & 04 \\
\hline
\end{tabular}

Fonte: Os autores (2020).

Nota: Dados obtidos conforme análise dos planos diretores municipais avaliados disponíveis on-line.

(1) Municípios com mais de 50.000 habitantes e menos de 100.000 habitantes.

(2) Municípios com mais de 100.000 habitantes.

No total dos 45 municípios gaúchos com mais de 50.000 habitantes, 91,1\% apresentam nos seus planos diretores o IPTU progressivo nos termos previstos no art. $7^{\circ}$ do Estatuto da

\footnotetext{
${ }^{12}$ Veja os casos de Tramandaí, que não define subutilização no Plano Diretor, asseverando que lei específica deverá contemplá-lo; Taquara, que traz o IPTU progressivo no Código Tributário quando da necessidade de lotear em imóveis que não estejam limpos, além de não trazer critérios para a subutilização; Carazinho, que não possui disposição específica, no Plano Diretor, para definir a subutilização, enquanto o Código Tributário Municipal traz a alíquota para ser aplicada em áreas previstas no Plano Diretor; Montenegro, que não traz critério somente para a subutilização; Campo Bom, que traz o IPTU progressivo no Código Tributário do município para terrenos vagos; Camaquã, que apresenta o conceito de vazio urbano a englobar glebas com subutilização na qual o uso seja inferior a 30\% do coeficiente; Venâncio Aires, que tem alíquotas maiores no Código Tributário Municipal, não progressivas, para imóveis não edificados; Cachoeira do Sul, que apresenta as disposições estudadas na Lei Orgânica; Erechim, que não tem critérios para a subutilização, mas apenas para áreas baldias; Bento Gonçalves, que somente tem a lei tributária do IPTU progressivo; Santa Cruz do Sul, que tem alíquotas progressivas para imóveis não edificados no seu Código Tributário; Canoas, que define alíquota progressiva para terrenos sem ocupação na legislação tributária municipal.

13 Alegrete, Campo Bom, Cachoeira do Sul, Camaquã, Canguçu, Carazinho, Cruz Alta, Estância Velha, Esteio, Farroupilha, Guaíba, Ijuí, Lajeado, Montenegro, Parobé, Taquara, Tramandaí, São Borja, Sapiranga, Santa Rosa, Sant'Ana do Livramento, Santo Ângelo, Vacaria e Venâncio Aires.

${ }^{14}$ Bagé, Bento Gonçalves, Cachoeirinha, Canoas, Caxias do Sul, Erechim, Novo Hamburgo, Passo Fundo, Pelotas, Porto Alegre, Rio Grande, Santa Cruz do Sul, Sapucaia do Sul, Santa Maria, São Leopoldo, Uruguaiana e Viamão.
} 
Cidade, enquanto que 8,9\% assim não procedem, nos termos apresentados no Gráfico 1 .

Gráfico 1 - \% de municípios gaúchos com mais de 50.000 habitantes que preveem o IPTU progressivo nos seus planos diretores

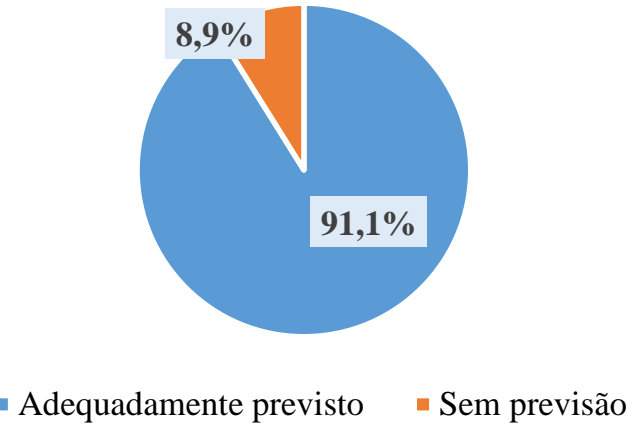

Fonte: Os autores (2020).

Nota: Dados compilados conforme análise dos planos diretores dos municípios gaúchos com mais de 50.000 habitantes.

2.2 Planos diretores que delimitam as áreas de aplicação do parcelamento, edificação ou utilização compulsórios

O percentual de 61,5\% dos municípios do Grupo A delimitam as áreas de aplicação do parcelamento, edificação ou utilização compulsórios, enquanto que 38,5\% não cumprem com este dever. No grupo de maior população, Grupo B, o percentual aumenta para $73,7 \%$ de cumprimento, enquanto que $26,3 \%$ dos municípios não apresentam essa delimitação, conforme a Tabela 2, a seguir apresentada.

Tabela 2 - Número de municípios gaúchos com mais de 50.000 habitantes que delimitam as áreas de aplicação do parcelamento, edificação e utilização compulsórios nos seus planos diretores

\begin{tabular}{c|c|c}
\hline $\begin{array}{c}\text { Municípios } \\
\text { gaúchos }\end{array}$ & $\begin{array}{c}\text { Planos diretores que delimitam as } \\
\text { áreas de aplicação do parcelamento, } \\
\text { edificação ou utilização } \\
\text { compulsórios }\end{array}$ & $\begin{array}{c}\text { Planos diretores que não delimitam } \\
\text { as áreas de aplicação do } \\
\text { parcelamento, edificação ou } \\
\text { utilização compulsórios }\end{array}$ \\
\hline Grupo A (1) & $16^{15}$ & 10 \\
Grupo B (2) & $14^{16}$ & 5 \\
TOTAL & 30 & 15 \\
\hline
\end{tabular}

Fonte: Os autores (2020).

Nota: Dados obtidos conforme análise dos planos diretores municipais avaliados disponíveis on-line.

(1) Municípios com mais de 50.000 habitantes e menos de 100.000 habitantes.

(2) Municípios com mais de 100.000 habitantes.

15 Alegrete, Camaquã, Carazinho, Cruz Alta, Estância Velha, Esteio, Farroupilha, Ijuí, Montenegro, Parobé, Sant'Ana do Livramento, São Borja, São Gabriel, Taquara, Tramandaí e Vacaria.

16 Bagé, Cachoeirinha, Canoas, Caxias do Sul, Erechim, Gravataí, Novo Hamburgo, Passo Fundo, Pelotas, Porto Alegre, Rio Grande, São Leopoldo, Sapucaia do Sul e Viamão. 
No total dos 45 municípios gaúchos com mais de 50.000 habitantes, 66,7\% apresentam a delimitação, enquanto que $33,3 \%$ assim não procederam, conforme apresentado no gráfico seguinte.

Gráfico 2 - \% de municípios gaúchos com mais de 50.000 habitantes que delimitam as áreas de aplicação do parcelamento, edificação ou utilização compulsórios nos seus planos diretores

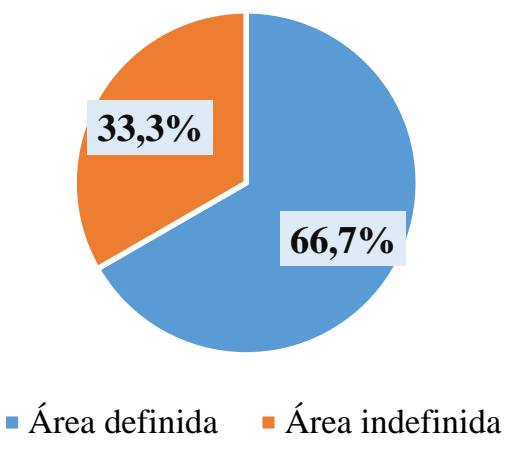

Fonte: Os autores (2020).

Nota: Dados compilados conforme análise dos planos diretores dos municípios gaúchos com mais de 50.000 habitantes.

\subsection{Critérios para imóvel subutilizado, não utilizado e não parcelado}

A análise dos planos diretores com critérios mínimos de definição de imóvel não utilizado, subutilizado ou não parcelado, de forma a possibilitar a posterior incidência do IPTU progressivo pormenorizado por meio de alíquotas progressivas, foi realizada através de várias expressões de busca relacionadas aos planos diretores e legislação esparsa. Observa-se que 42,3\% dos municípios do Grupo A assim procedem, enquanto que 57,7\% não possuem tais definições nos planos diretores. Nos municípios do Grupo B, os percentuais pioram e alcançam $31,6 \%$ e 68,4\%, respectivamente. Municípios que não definiram subutilização ficaram naturalmente excluídos, conforme a tabela seguinte. 
Tabela 3 - Número de municípios gaúchos com mais de 50.000 habitantes que apresentam critérios mínimos para a não utilização, subutilização e não parcelamento nos seus planos diretores e/ou em legislação correlata

\begin{tabular}{c|c|c}
\hline $\begin{array}{c}\text { Municípios } \\
\text { gaúchos }\end{array}$ & $\begin{array}{c}\text { Legislação municipal apresenta } \\
\text { critérios mínimos de não utilização, } \\
\text { subutilização e não parcelamento }\end{array}$ & $\begin{array}{c}\text { Legislação municipal não apresenta } \\
\text { critérios mínimos de não utilização, } \\
\text { subutilização e não parcelamento }\end{array}$ \\
\hline Grupo A (1) & $11^{17}$ & 15 \\
Grupo B (2) & $6^{18}$ & 13 \\
TOTAL & 17 & 28 \\
\hline
\end{tabular}

Fonte: Os autores (2020).

Nota: Dados obtidos conforme análise da legislação municipal disponível on-line, especialmente dos planos diretores.

(1) Municípios com mais de 50.000 habitantes e menos de 100.000 habitantes.

(2) Municípios com mais de 100.000 habitantes.

No total, a considerar todos os municípios gaúchos com mais de 50.000 habitantes, o percentual de municípios que procederam a esta definição alcançou $37,8 \%$, enquanto que $62,2 \%$ assim não procederam, nos termos do Gráfico 3. Nota-se que, não obstante a busca tenha tido como foco os planos diretores, utilizou-se de várias expressões para a localização de eventuais leis específicas sobre a matéria.

Gráfico 3 - \% de municípios gaúchos com mais de 50.000 habitantes que apresentam critérios para imóvel subutilizado, não utilizado e não parcelado no seu plano diretor e/ou em legislação correlata

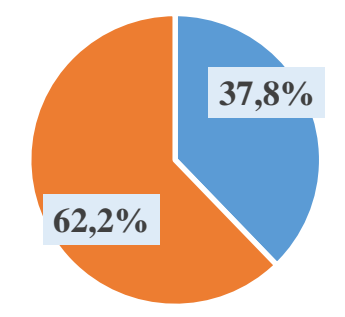

- Critérios mínimos apresentados na legislação municipal

- Sem critérios mínimos na legislação municipal

Fonte: Os autores (2020).

Nota: Dados obtidos conforme análise da legislação municipal disponível on-line, especialmente dos planos diretores.

\footnotetext{
${ }^{17}$ Alegrete, Cachoeira do Sul, Camaquã, Cruz Alta, Farroupilha, Guaíba, Ijuí, Montenegro, Sant’Ana do Livramento, Vacaria e Venâncio Aires.

18 Alvorada, Bagé, Passo Fundo, Rio Grande, São Leopoldo e Viamão.
} 


\subsection{Alíquotas do IPTU progressivo}

Por fim, quanto à existência de previsão de alíquotas específicas em relação ao IPTU progressivo, observa-se, nos municípios do Grupo A, que somente 30,8\% possuem tal disciplina normativa, enquanto que 69,2\% assim não procederam. Nos municípios do Grupo B o quadro não se altera muito, com percentuais de $31,6 \%$ e $68,4 \%$, respectivamente, conforme a Tabela 4.

Tabela 4 - Número de municípios gaúchos com mais de 50.000 habitantes que apresentam legislação municipal tratando da alíquota progressiva do IPTU

\begin{tabular}{c|c|c}
\hline $\begin{array}{c}\text { Municípios } \\
\text { gaúchos }\end{array}$ & $\begin{array}{c}\text { Com previsão da alíquota do IPTU } \\
\text { progressivo }\end{array}$ & $\begin{array}{c}\text { Sem previsão da alíquota do IPTU } \\
\text { progressivo }\end{array}$ \\
\hline Grupo A (1) & $8^{19}$ & 18 \\
Grupo B (2) & $6^{20}$ & 13 \\
TOTAL & 14 & 31 \\
\hline
\end{tabular}

Fonte: Os autores (2020).

Nota: Dados obtidos conforme análise da legislação municipal disponível on-line, em especial dos planos diretores municipais.

(1) Municípios com mais de 50.000 habitantes e menos de 100.000 habitantes.

(2) Municípios com mais de 100.000 habitantes.

Quando a análise foca na totalidade dos entes locais com mais de 50.000 habitantes, mantem-se o percentual de $31,1 \%$ de municípios com leis específicas a normatizar o IPTU progressivo e 68,9\% que não possuem, nos termos do Gráfico 4.

Gráfico 4 - \% de municípios gaúchos com mais de 50.000 habitantes que apresentam alíquota progressiva do IPTU na sua legislação

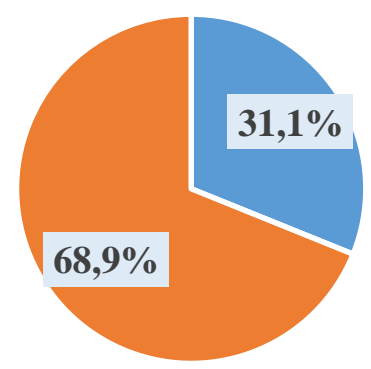

- Apresenta alíquota progressiva = Não apresenta alíquota progressiva

Fonte: Os autores (2020).

Nota: Dados obtidos conforme análise da legislação municipal disponível on-line, especialmente dos planos diretores.

Entretanto, é preciso a análise de todas as informações já coletadas, sistemicamente. A

${ }^{19}$ Campo Bom, Carazinho, Esteio, Guaíba, Ijuí, Taquara, Sant’Ana do Livramento e Sapiranga.
${ }^{20}$ Bagé, Bento Gonçalves, Passo Fundo, Rio Grande, Viamão e Porto Alegre. 
levar em conta que a efetividade do IPTU progressivo requer a sua previsão no Plano Diretor, bem como a definição do que seja imóvel não utilizado, subutilizado e não parcelado, associado às alíquotas específicas do IPTU progressivo definido em lei, pode-se observar que dos 8 municípios que possuem a legislação específica do IPTU do Grupo A, somente 2 possuem os demais critérios no Plano Diretor ou eventuais leis específicas: Sant'Ana do Livramento e Ijuí. Dos municípios do Grupo B, dos 6 que possuem a legislação específica do IPTU, 4 têm as definições respectivas no Plano Diretor ou eventual legislação específica: Bagé, Passo Fundo, Rio Grande e Viamão. Assim, dos 45 municípios com mais de 50.000 habitantes do Rio Grande do Sul, apenas 6 estão em condições de efetivar o IPTU progressivo, ou seja, em 13,3\% é possível aceitar a possibilidade de eficácia jurídica deste instituto, conforme se observa no Gráfico 5.

Gráfico 5 - \% de municípios gaúchos com mais de 50.000 habitantes que apresentam eficácia do IPTU progressivo - edificação, parcelamento e utilização compulsórios

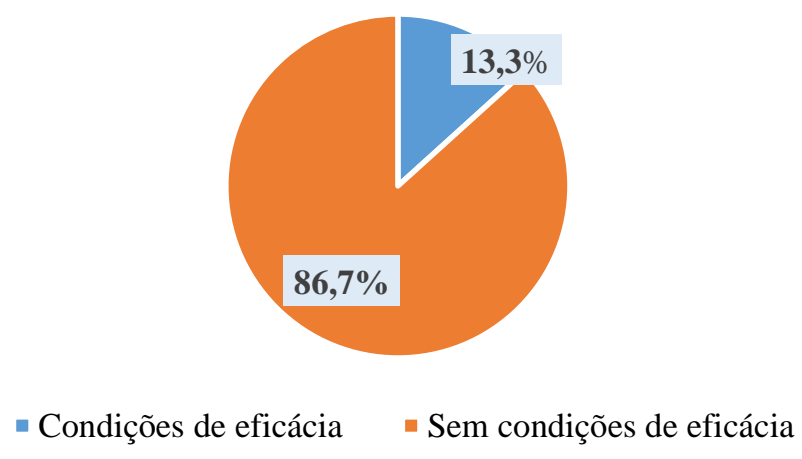

Fonte: Os autores (2020).

Nota: Dados obtidos conforme análise da legislação municipal disponível on-line, especialmente dos planos diretores.

\section{Conclusão}

A Constituição Federal de 1988 é muito enfática ao salientar a função social da propriedade. Aliás, o próprio direito fundamental de propriedade tem por pressuposto a sua função social.

No que tange à propriedade urbana, compete à União definir as diretrizes gerais do desenvolvimento urbano, o que foi feito com o Estatuto da Cidade. Entretanto, é da competência das municipalidades aplicar os instrumentos previstos neste regramento geral. É o que ocorre com o parcelamento, edificação e utilização compulsórios e o IPTU progressivo.

Salienta-se a autonomia que os municípios desfrutam na ordem jurídica brasileira, 
enquanto entes integrantes do pacto federativo, para moldar os instrumentos da política urbana de acordo com as suas particularidades e singularidades. É o que ocorre com o parcelamento, edificação e utilização compulsórios, a fazer com que os municípios definam, especificamente, os critérios para considerar um imóvel subutilizado ou não edificado ou a área na qual incida a obrigação de parcelamento.

É com base na autonomia municipal que várias são as políticas a serem implementas, ora de cunho mais liberal e menos restritiva, ora de cunho mais social e mais intervencionista. De toda a sorte, há uma obrigação dos entes municipais de disciplinar a matéria e é esse o foco da pesquisa, sem adentar no mérito das políticas em si.

Para que o IPTU progressivo possa ser aplicado enquanto instrumento da política urbana é preciso que o município discipline adequadamente o parcelamento, edificação e utilização compulsórios, pois é o não cumprimento destas compulsoriedades que permite a sua aplicação. Para tanto, com base na legislação municipal, especialmente o Plano Diretor, deve o município notificar o proprietário, que terá o prazo mínimo de um ano - prazo definido na legislação local - para protocolar o projeto no órgão competente da municipalidade. Se assim não ocorrer, pode incidir o IPTU progressivo. Se o projeto for protocolado terá o prazo mínimo de dois anos este prazo também deve estar previsto em lei local, após a aprovação do projeto, para o seu início, que, se não ocorrer, possibilita a incidência do IPTU progressivo, nas alíquotas definidas em lei. Após a incidência do IPTU progressivo por 5 anos pode ocorrer a desapropriação com pagamento em títulos da dívida pública, o que não é alvo desta pesquisa.

Como o foco da pesquisa é averiguar a hipótese de ineficácia jurídica do IPTU progressivo nos municípios gaúchos com mais de 50.000 habitantes, procedeu-se à análise da legislação desses 45 municípios.

Quanto aos planos diretores que contemplam minimamente o IPTU progressivo, o resultado foi positivo para $91,1 \%$ dos entes locais. Já no que tange à delimitação, nos planos diretores, das áreas de aplicação do parcelamento, edificação ou utilização compulsórios, o percentual cai para 66,7\%. Os critérios para a identificação de imóveis não parcelados, não edificados e, principalmente, não utilizados, estão presentes em somente 37,8\% dos municípios. Por fim, somente $31,1 \%$ dos entes municipais estabeleceram as alíquotas para o IPTU progressivo.

Tais dados não são suficientes. É preciso analisar os municípios que, cumulativamente, atendam aos quatro critérios pesquisados, o que conduz a somente 13,3\% dos municípios, a confirmar a hipótese da baixíssima ineficácia do IPTU progressivo no tempo enquanto política urbana nos municípios gaúchos com mais de 50.000 habitantes. 
As causas dessa baixíssima eficácia jurídica, que podem ser variadas e múltiplas, não se encontram nos objetivos deste estudo científico. Especula-se, apenas para constar, o caráter naturalmente conflitivo dessas políticas de restrição da propriedade, a atingir parcelas economicamente poderosas, a postura mais liberal dos representantes da sociedade e a própria cultura que forjou o povo brasileiro em relação ao direito de propriedade. Pelas mesmas razões não se pesquisou a eficácia social ou efetividade nos $13,3 \%$ dos municípios em que o IPTU progressivo possui eficácia jurídica, o que poderia conduzir a resultados ainda mais desalentadores, o que não significa ignorar que a ordem jurídica, por si, não basta, afinal de contas, como afirmaram Cavalcante e Leôncio (2019, p. 1) “[...] os lírios não nascem da lei.”. Todavia, sem a lei, sequer há chances de "lírios".

\section{Referências}

ÁVILA, Humberto. Teoria dos Princípios: da definição à aplicação dos princípios jurídicos. 3. ed. São Paulo: Malheiros, 2004.

BARROSO, Luís Roberto. O Direito Constitucional e a efetividade de suas normaslimites e possibilidades da constituição brasileira. 2. ed. Rio de Janeiro: Renovar, 1993.

BRASIL. [Constituição (1988)]. Constituição da República Federativa do Brasil de 1988. Brasília, DF: Presidência da República, [2020]. Disponível em:

http://www.planalto.gov.br/ccivil_03/constituicao/constituicao.htm. Acesso em: 15 fev. 2020.

BRASIL. Lei $\mathbf{n}^{\circ} \mathbf{1 0 . 2 5 7}$, de 10 de julho de 2001. Regulamenta os arts. 182 e 183 da Constituição Federal, estabelece diretrizes gerais da política urbana e dá outras providências. Brasília, DF: Presidência da República, [2020]. Disponível em: http://www.planalto.gov.br/ccivil_03/leis/leis_2001/110257.htm. Acesso em: 10 mar. 2020.

BOBBIO, Norberto. Estado, governo, sociedade: para uma teoria geral da política. 12. ed. São Paulo: Paz e Terra, 2005.

BONAVIDES, Paulo. Do Estado Liberal ao Estado Social. 6. ed. MALHEIROS EDITORES: [S. l.], 1996.

BRAJATO, Dânia; DENALDI, Rosana. O impasse na aplicação do Estatuto da Cidade: explorando o alcance do PEUC em Maringá - PR (2009-2015). Rev. Bras. Estud. Urbanos Reg., São Paulo, v. 21, n. 1, p. 45-62, jan./abr. 2019. DOI: https://doi.org/10.22296/23171529.2019v21n1p45. Disponível em: https://rbeur.anpur.org.br/rbeur/article/view/5768. Acesso em: 19 jun. 2020.

CANOTILHO, José Joaquim Gomes. Constituição Dirigente e vinculação do legislador. Coimbra: Coimbra Editora, 1994.

CAVALCANTE, André Felipe Bandeira; LEÔNCIO, Érica Milena Carvalho Guimarães. "As leis não bastam, os lírios não nascem da lei": IPTU progressivo no tempo como possibilidade 
de efetivação da função social da propriedade no Brasil. Revista Brasileira de Gestão Urbana, v. 11, p. 1-10, 2019. DOI: https://doi.org/10.1590/2175-3369.011.001.AO08. Disponível em: https://www.scielo.br/scielo.php?script=sci_arttext\&pid=S217533692019000100223\&tlng=pt. Acesso em: 10 jun. 2020.

COMPARATO, Fábio Konder. Direitos e deveres fundamentais em matéria de propriedade. Revista CEJ, Brasília, v. 1, n. 3, p. 92-99, set./dez. 1997. Centro de Estudos Judiciários. Conselho da Justiça Federal. Disponível em: https://revistacej.cjf.jus.br/revcej/issue/view/13. Acesso em: 18 jun. 2020.

COMTE, Auguste. Curso de filosofia positiva; Discurso sobre o espírito positivo; Discurso preliminar sobre o conjunto do positivismo; Catecismo positivista. São Paulo: Abril Cultural, 1978.

CORRALO, Giovani da Silva. Curso de Direito Municipal. São Paulo: Atlas, 2011.

CORRALO, Giovani da Silva. Município: autonomia na Federação brasileira. 2. ed. Curitiba: Juruá, 2014.

COSTA, Fábio Custódio; SANTORO, Paula Freire. O processo de implementação do Parcelamento, Edificação ou Utilização Compulsórios: o caso dos imóveis não utilizados nos Distritos Centrais de São Paulo (SP). Rev. Bras. Estud. Urbanos Reg., São Paulo, v. 21, n. 1, p. 63-79, jan./abr. 2019. DOI: https://doi.org/10.22296/2317-1529.2019v21n1p63. Disponível em: https://www.scielo.br/scielo.php?script=sci_arttext\&pid=S231715292019000100063\&lang=pt\#fn19. Acesso em: 19 jun. 2020.

COULANGES, Fustel de. A cidade antiga. 4. ed. São Paulo: Martins Fontes, 1998.

DENALDI, Rosana et al. Parcelamento, edificação ou utilização compulsórios e IPTU progressivo no tempo: regulamentação e aplicação. Brasília: Ministério da Justiça, Ipea, n. 56, 2015, 321 p. Série Projeto Pensando o Direito. Disponível em:

http://pensando.mj.gov.br/publicacoes/?pub_id=1001128. Acesso em: 18 jun. 2020.

DUGUIT, Léon. Las transformaciones generales del derecho privado desde el código de Napoléon. Valparaíso: EDEVAL, 1987.

FERREIRA FILHO, Manoel Gonçalves. A propriedade e sua função social. Revista de Direito Agrário, Brasília, ano 9, n. 8, p. 29-36, 1982.

FIORILLO, Celso Antônio Pacheco. Estatuto da Cidade comentado: Lei n. 10.257/2001. 6. ed. São Paulo: Saraiva, 2014.

FROSI, Ricardo Gehlen. Do direito de propriedade privada e da propriedade agrária: estudos sobre a função social. Passo Fundo: Ediupf, 1998.

GRAU, Eros Roberto. A ordem econômica na Constituição de 1988. 12. ed. [S.l.]: MALHEIROS EDITORES, 2007.

INSTITUTO BRASILEIRO DE GEOGRAFIA E ESTATÍSTICA (IBGE). Estimativas da população residente no Brasil e Unidades da Federação com data de referência em $1^{\circ}$ de 
CORRALO, Giovani da Silva; MATTJIE, Diego. A função social da propriedade e o IPTU progressivo: análise dos municípios gaúchos com mais de $\mathbf{5 0 . 0 0 0}$ habitantes

julho de 2019, [S. l.]: Diretoria de Pesquisas - Coordenação de População e Indicadores Sociais, [2019]. Disponível em: https://www.ibge.gov.br/estatisticas/sociais/populacao/9103estimativas-de-populacao.html?=\&t=resultados. Acesso em: 15 fev. 2020.

LEAL, Rogério Gesta. A função social da propriedade e da cidade no Brasil: aspectos jurídicos e políticos. Porto Alegre: Livraria do Advogado, 1998.

LOCKE, John. Segundo tratado sobre o governo civil e outros escritos: ensaio sobre a origem, os limites e os fins verdadeiros do governo civil. Petrópolis: Vozes, 1994.

MARQUES, Carolina Corso Rodrigues. Legislação urbanística aplicada. Porto Alegre: SAGAH, 2018.

MORAES, José Diniz de. A função social da propriedade e a Constituição de 1988. [S. l.]: MALHEIROS EDITORES, 1999.

OLIVEIRA, Álvaro Borges de; LACERDA, Emanuela Cristina Andrade. Evolução constitucional da propriedade constitucional. Estudios Constitucionales, Santiago, año 9, n. 2, p. 713-740, 2011. Centro de Estudios Constitucionales de Chile, Universidad de Talca. Disponível em: https://scielo.conicyt.cl/scielo.php?script=sci_arttext\&pid=S071852002011000200018\&lng=en\&tlng=en. Acesso em: 20 jun. 2020.

PONTES, David Gomes. Função Social da Propriedade: o IPTU progressivo no tempo em razão de seu descumprimento e a legislação do Município de Sobral-CE. 2017. Dissertação (Mestrado Interinstitucional em Direito) - Universidade Federal de Santa Catarina, Florianópolis, 2017. Disponível em:

https://repositorio.ufsc.br/bitstream/handle/123456789/185480/PDPC1332-D.pdf?sequence=1\&isAllowed=y. Acesso em: 28 jun. 2020.

RIBEIRO, Maria de Fátima. O IPTU como instrumento de intervenção no uso e ocupação do solo urbano conforme disposições do estatuto da cidade. Scientia Iuris, Londrina, v. 5/6, n. 1, p. 232-258, 2001/2002. DOI: http://dx.doi.org/10.5433/2178-8189.2002v5n0p232. Disponível em: http://www.uel.br/revistas/uel/index.php/iuris/issue/view/737. Acesso em: 18 jun. 2020.

ROUSSEAU, Jean-Jacques. Discurso sobre a origem e os fundamentos da desigualdade entre os homens. 2. ed. São Paulo: Martins Fontes, 1999.

SARLET, Ingo Wolfgang. A Eficácia dos Direitos Fundamentais. 6. ed. Porto Alegre: Livraria do Advogado, 2006.

SILVA, José Afonso da. Princípios do Processo de Formação das Leis no Direito Constitucional. São Paulo: Revista dos Tribunais, 1964. 